\title{
Biomimicry interventions for addressing global environmental challenges
}

\author{
Olusegun Aanuoluwapo Oguntona ${ }^{\mathrm{a} *}$, Clinton Aigbavboa ${ }^{\mathrm{b}}$ \\ ${ }^{a, b}$ SARChI in Sustainable Construction Management and Leadership in the Built Environment, Faculty of Engineering and the Built Environment, \\ University of Johannesburg, South Africa
}

\begin{abstract}
Many damages have been done globally to the natural environment, all in a bid to providing essential amenities and addressing the infrastructural deficit. These actions have resulted in increased carbon footprint, excessive heat, loss of biodiversity, increase in pollutant level in the atmosphere, and fluctuating weather conditions among many others. One of the latest sustainability drives that aim to address the environmental challenges facing the world today is biomimicry. As a new field that seeks to study, extract and emulate the fantastic processes and mechanisms operational in nature, biomimicry has become the most accessible and available source of productive ideas and solutions to the global environmental issues. Currently, there have been records of sustainable and innovative technologies inspired by nature that provides solutions to these problems. This paper aims to create awareness around the selected few of the biomimetic solutions that address the diverse environmental challenges facing humanity with a focus on energy and water issues. Been aware of the existence of these nature-inspired innovative technologies and solutions and their mode of operation is believed will be a giant step in encouraging their adoption and implementation.
\end{abstract}

(C) 2019 The Authors. Published by Budapest University of Technology and Economics \& Diamond Congress Ltd. Peer-review under responsibility of the scientific committee of the Creative Construction Conference 2019.

Keywords: assessment tools; built environment; construction materials; green building; sustainability.;

\section{Introduction}

The challenges facing the world today are manifesting themselves in the economic, political and environmental dimensions. The study of [1] describes global challenges as issues, factors or circumstances which has a significant potential for threatening global stability. As highlighted by [2], issues such as terrorism, global warming, natural disasters, nuclear weapon proliferation, diseases outbreak, migration, population growth, political instabilities and continuous thinning of the ozone shield are few of the numerous challenges. Other global issues include depleting clean air and water, climate change, energy supply, geopolitical conflicts, depleting natural resources, financial upheavals and food crisis [3]. The 2013 report by the World Economic Forum (WEF) also identified rising greenhouse gas (GHG) emissions, water supply crises, severe income disparity, chronic fiscal imbalances and mismanagement of an ageing population as the top five global risks to manifest over the next ten years [1]. As suggested by [4], how we can encourage a change in human behaviour, influence political will, and advance science and technology are questions to be posted in other to address these global challenges. However, environmental issues remain dominant among the numerous challenges facing the world, with the impacts cutting across all human sectors. Hence, the introduction of 
sustainable development (SD) or sustainability concepts as a means of combating and mitigating the numerous environmental issues facing humanity. In recognition of the need to address global challenges, the general assembly of the United Nations (UN) in 2015 adopted the 2030 agenda for SD which comprises of seventeen (17) sustainable development goals (SDGs) as presented in Table 1. The new agenda which reached its fourth year of implementation this year 2019 emphasises a comprehensive strategy to achieving SD for everyone as against the millennium development goals (MDGs) which lapsed in the year 2015.

Table 1. Sustainable development goals [5].

\begin{tabular}{|c|c|c|}
\hline Goal & Description & \\
\hline Goal 1 & No Poverty & End poverty in all its forms everywhere \\
\hline Goal 2 & Zero Hunger & $\begin{array}{l}\text { End hunger, achieve food security and improved nutrition and promote } \\
\text { sustainable agriculture }\end{array}$ \\
\hline Goal 3 & Good Health and Well-Being & Ensure healthy lives and promote well-being for all at all ages \\
\hline Goal 4 & Quality Education & $\begin{array}{l}\text { Ensure inclusive and equitable quality education and promote lifelong learning } \\
\text { opportunities for all }\end{array}$ \\
\hline Goal 5 & Gender Equality & Achieve gender equality and empower all women and girls \\
\hline Goal 6 & Clean Water and Sanitation & Ensure availability and sustainable management of water and sanitation for all \\
\hline Goal 7 & Affordable and Clean Energy & Ensure access to affordable, reliable, sustainable and modern energy for all \\
\hline Goal 8 & Decent Work and Economic Growth & $\begin{array}{l}\text { Promote sustained, inclusive and sustainable economic growth, full and } \\
\text { productive employment and decent work for all }\end{array}$ \\
\hline Goal 9 & Industry, Innovation and Infrastructure & $\begin{array}{l}\text { Build resilient infrastructure, promote inclusive and sustainable } \\
\text { industrialisation and foster innovation }\end{array}$ \\
\hline Goal 10 & Reduced Inequality & Reduce inequality within and among countries \\
\hline Goal 11 & Sustainable Cities and Communities & Make cities and human settlements inclusive, safe, resilient and sustainable \\
\hline Goal 12 & Responsible Consumption and Production & Ensure sustainable consumption and production patterns \\
\hline Goal 13 & Climate Action & Take urgent action to combat climate change and its impacts \\
\hline Goal 14 & Life Below Water & $\begin{array}{l}\text { Conserve and sustainably use the oceans, seas and marine resources for } \\
\text { sustainable development }\end{array}$ \\
\hline Goal 15 & Life on Land & $\begin{array}{l}\text { Protect, restore and promote sustainable use of terrestrial ecosystems, } \\
\text { sustainably manage forests, combat desertification, and halt and reverse land } \\
\text { degradation and halt biodiversity loss }\end{array}$ \\
\hline Goal 16 & Peace and Justice Strong Institutions & $\begin{array}{l}\text { Promote peaceful and inclusive societies for sustainable development, provide } \\
\text { access to justice for all and build effective, accountable and inclusive } \\
\text { institutions at all levels }\end{array}$ \\
\hline Goal 17 & Partnerships to Achieve the Goal & $\begin{array}{l}\text { Strengthen the means of implementation and revitalise the global partnership } \\
\text { for sustainable development }\end{array}$ \\
\hline
\end{tabular}

Sustainability and SD are often seen as two confusing terminologies describing with different meanings. The term SD was captured in the 1987 report of the Brundtland Commission giving the most commonly-cited definition [6]. The commission defined SD as development that meets the needs of the present without compromising the ability of future generations to meet their own needs. SD is closely associated with supporting, ensuring and promoting a healthy human and natural environment [7]. Sustainability, on the other hand, means the use of natural resources in such a condition of equilibrium that they do not reach decay, depletion and an unrenewable point and can be handed down to the future generations [8]. Regardless of the definitions of sustainability and SD, we can infer that both have the potential to address global environmental issues effectively. In the pursuit and paradigm shift of the human environment towards sustainability, several concepts have been developed. As identified by [9], few of the sustainability concepts include the Natural Step, cradle to cradle, cradle to grave, lean construction, lean manufacturing, biomimicry, ecological economics, Factor 4 and Factor 10, ecological rucksack, biophilia, eco-efficiency, and ecological footprint among others. 
Oguntona and Aigbavboa/ Proceedings of the Creative Construction Conference (2019) 015

https://doi.org/10.3311/CCC2019-015

As a relatively new field, biomimicry has become prominent among the sustainability concepts with a strong potential to solve human challenges in a sustainable manner. Biomimicry operates by identifying, studying, emulating and integrating ideas from nature to solve different problems facing humanity [10]. As described by [11], biomimicry is the quest of stakeholders and professionals in exploring nature's ingenuity (self-sustaining ecosystems, photosynthesis, natural medicines, self-assembly, self-cleaning) and then emulating these designs and processes to solve human problems. Hence, this paper presents biomimicry technologies (commercialised, developed and in the development stage) that address energy and water issues which are notable among the global environmental challenges. The paper presents a review of related literature on nature-inspired methodologies and solutions. The final section of the paper showcases and presents an evaluation of the biomimetic solutions identified, draws conclusions and proffer recommendations.

\section{Historical background and overview of biomimicry}

Historically, early humans relied solely on the natural world for survival and sustenance. There is a high dependency on nature for the provision of food, shelter, agricultural tools, weapons and hunting tools, medicine and pharmaceutical needs among others. Also, around 500 B.C, Greek philosophers perceive and consult the natural world for ideas that are harmonious and aesthetically pleasing [12]. Leonardo da Vinci's flying machines is a notable example of early scientist's and designer's practice of drawing inspiration from nature [13]. By mere observation and in-depth examination of nature, early scientists and innovators amass vital information and ideas about functionality, efficiency and effective resource utilisation. The interrelation between the forms, functions and ecosystems of natural organisms revealed a robust system and presented a rich source of sustainable inspiration for application in different sectors and fields. As informed by [14], the natural environment adheres to a remarkable morphological principle in generating interfaces rather than shields in enabling most favourable passage of matter. As affirmed by [15], strategies in nature can inspire solutions to human challenges.

Nature has been able to adapt and evolve to the varying conditions on earth through its over 3.8 billion years of evolution $[11,16]$. By meeting its own needs and solving its challenges, the natural world sustains itself thereby offering a knowledge deposit of innovative ideas and solutions to the numerous challenges the human environment is grappling with daily. Biomimicry, therefore, seeks to study and emulate the designs and processes in nature to solve human challenges in a sustainable manner. The term 'biomimicry' first appeared in the year 1982 as part of Connie L. Merrill's doctoral thesis. The thesis is titled "Biomimicry of the Dioxygen Active Site in the Copper Proteins Hemocyanin and Cytochrome Oxidase" [17]. A careful perusal of the thesis, however, reveals no connection to nature nor draws inspiration from the operations in the natural world. Biomimicry then became popularised in the year 1997 through the book authored by Janine M. Benyus, a biologist, and co-founder of Biomimicry Guild. The book titled "Biomimicry: Innovation Inspired by Nature" projected Benyus as the founder of this new field of study.

The practice of learning and drawing inspiration from nature for innovative solutions has seen the birth of multiple terms such as biomimesis, bioanalogous design, bionics, biognosis, bio-inspired design, biomimetics, bioinspiration, biodesign, and biorobotics among others $[16,18,19]$. The field or sector determine the term to employ for its application. For example, drawing inspiration from nature for application in the field of robotics will result in the use of the term biorobotics. Since this study focuses on biomimicry, the study of [20] affirm that there is no difference between 'biomimetics' and 'biomimicry'. Considering the sound of the terminology, biomimicry is perceived to be some branch of biological science. The biological and scientific affiliation to biomimicry only provides an avenue for studying and learning about the forms, processes and strategies in nature [21].

Literature has recorded several definitions of biomimicry since its research and application gained momentum in recent years. As defined by [22] and [23], biomimicry is the process of creating sustainable designs and solutions through the conscious study and emulation of natural forms, strategies, processes and ecosystems. Biomimicry heralds a paradigm shift from exploiting and extracting from nature to that which studies and learns from it. The application of biomimicry for birthing eco-friendly developments is gaining overwhelming significance. Notable among the breakthroughs recorded in the application of biomimicry spans through the field of medicine, robotics, engineering, environmental 
Oguntona and Aigbavboa/ Proceedings of the Creative Construction Conference (2019) 015

https://doi.org/10.3311/CCC2019-015

sciences, pharmaceuticals and security among numerous others. This paper, therefore, presents biomimicry applications for addressing the present-day global environmental challenges in other to provoke a conscious shift towards this new field of study with innumerable potentials.

\section{Biomimicry solutions to global environmental challenges}

Biomimicry has inspired environmental-friendly innovative breakthroughs in different sectors with remarkable physical, chemical and mechanical characteristics [24]. According to [25], other advantageous qualities these technologies posses include low weight and reduced manufacturing costs compared to the traditional ones. It is, therefore, imperative for all stakeholders to consult with nature in learning solutions for adapting, mitigating and reversing the various environmental challenges facing humanity today. Below are carefully selected biomimicry solutions out of the pool of many for addressing global environmental challenges as compiled by AskNature [26]. This paper addresses two major areas where biomimicry has been successful in innovating technologies that tackle global environmental challenges namely biomimicry solutions for energy challenges and biomimicry solutions for water challenges.

\subsection{Biomimicry solutions for energy challenges}

Energy security, rising energy costs and most especially the adverse environmental impacts of energy production, generation and distribution are necessitating the research, development and investments in renewable energy sources. However, the application of biomimicry has seen the development of clean and renewable energy as a way of addressing global environmental challenges emanating from energy-related issues. An example is the Solar Botanic energy harvesting trees which are artificial trees that convert wind energy and electromagnetic waves from the sun via its nanoleaf technology. Innovated by SolarBotanic Ltd and still at the development stage, this new bio-inspired solar/wind energy technology aims to energise the future by providing renewable, carbon-free and clean energy through the combination of wind and solar power. Through the photosynthetic cycle of their leaves, plants have been maximally harnessing the solar radiation received on the earth surface. Solar Botanic energy harvesting trees aims to emulate the same process of photosynthesis by using electromagnetic collectors (Nantennas), which are lower in costs and with improved efficiency (up to 92\%) compared to conventional silicon-based solar cells. When commercialised, this technology has the potential for reducing energy costs per $\mathrm{kWh}$, increasing output and improving return on investment (ROI) which are the significant challenges hindering renewable energy deployments.

Power Plastic solar cell technology innovated by Konarka Technologies Inc. is another example of biomimicry breakthroughs in energy solutions. Konarka Power Plastic thin film dye-sensitised solar cells is a photovoltaic material that captures and converts outdoor and indoor light to direct current (DC) electrical energy. This technology is inspired by the process where a continuous influx of photons generates a continuous flow of electrons along the electron transport chain in plants. The process of capturing and converting energy in plants informed a low-temperature, lowcost and high-speed method of developing flexible, plastic, nanocrystalline solar cells. The energy produced from this technology can be stored for later use, converted to other forms or immediately used with potential for application in broad range areas such as remote and portable power, buildings, sensing, computing, communications and lighting.

Another nature-inspired technology is the Dye Solar Cell Technology innovated by Dyesol, described as 'artificial photosynthesis' using an electrolyte, a layer of titania (a pigment used in white paints and toothpaste) and ruthenium dye sandwiched between glass. The light striking the dye excites electrons which are absorbed by the titania to become electric current multiple times stronger compared to that found in natural photosynthesis in plants. The manufacture of this technology is lower in cost and uses embodied energy. Dyesol's solar cell technology produces more efficient electricity even in low light conditions compared to the traditional silicon-based photovoltaic technology.

Energy consumption in buildings and the CI as a whole is enormous. Energy use in cooling and heating buildings accounts for a significant percentage of the total energy consumed. RavenBrick smart walls and windows (thermallytintable glass and thermally dynamic walls) by RavenBrick LLC is another bio-inspired innovation that addresses 
Oguntona and Aigbavboa/ Proceedings of the Creative Construction Conference (2019) 015

https://doi.org/10.3311/CCC2019-015

energy issues. It emulates the passive pigmentation and passive thermoregulation strategy found in natural organisms such as cephalopods and many lizard species. This technology maximises natural sunlight to save on lighting and improve the indoor quality for occupants by maintaining comfortable temperatures.

\subsection{Biomimicry solutions for water challenges}

Another major challenge facing the world are water-related in terms of provision and access to clean, affordable and safe water. Most of these challenges are notable among developing countries where there have been records of draught, water-borne diseases and epidemics (due to sick and unhealthy water sources and channels), and other water-related challenges. Biomimicry as a pool of sustainable ideas has propelled the innovation, development and commercialisation of technologies that address global environmental challenges that are water-related. Water filters innovated by Baleen Filters is a notable example of nature-inspired technologies that address water challenges. Baleen Filter's water filters are non-pressurised, efficient, self-cleaning water filtering system that filters and purifies water without the use of chemicals. Baleen Filter was inspired based on studies on whales and patented by the University of South Australia. Baleen as a filter mechanism enables filter-feeding whales to filter small fishes and other aquatic organisms during feeding. Combining the sweeping action of the tongue and the reversing water flows as the whale dives and re-surface during feeding enables them to capture and strain food, thereby cleaning their baleen against their next dive. The system is a greener path to water re-use and recycling.

Another bio-inspired solution that addresses water-related challenges is the BioHaven floating islands innovated by Floating Island International. This technology is inspired by how natural floating islands and natural wetlands filter sediments and nutrients out of surface water, generally emulating how a wetland ecosystem functions. BioHaven floating islands are created using non-toxic, durable post-consumer plastics and vegetated with native plants. This technology is useful for reducing total suspended solids and dissolved organic carbon in waterways and are perfectly fit for areas with fluctuating water levels due to their floating attributes.

Aquaporin membrane technology by Aquaporin is a water filtration and purification technology. This technology is inspired by Aquaporins who are selective membrane channel proteins found in the lipid bilayer of living cells that aid the transportation of water across the cell membrane while excluding any particles that are not water. Based on this process and strategy found in nature, Aquaporin can perfect the formulation of low-energy water filtration and purification technology which can be employed in industrial and household structures. This technology is also able to solve the inefficient and energy-intensive problems associated with the existing water filtration and purification techniques.

Green infrastructure stormwater control innovated by Numerous cities worldwide is a stormwater control and management system that is inspired by nature. In a natural ecosystem, the vegetation and soil therein provide a filtering mechanism through above-ground structures for water runoff. The above-ground structures slow down water runoff, allowing it to sink into the soil making sediments settle out as it moves through the vibrant soil ecosystem of fungi, bacteria, plant roots, and other organisms. Due to many hard surfaces and structures in our cities such as buildings, sidewalks, parking lots, and roads among others, stormwater is prevented from soaking into the ground as it would in a natural ecosystem of soils and plants. Also, water runoff due to rainstorm and stormwater overflow combines contaminants and pollutants such as pesticides, oil and grease, metals, plastics and many others that end up in surrounding waterways that serve as drinking water sources. With bio-inspired innovations like the green infrastructure stormwater control technology, concerns over the management of stormwater which have been around for years will be a thing of the past.

\section{Conclusion and recommendations}

Biomimicry seeks to study and infer the excellent methods, strategies, forms, and ecosystems in nature to proffer sustainable solutions to the problems facing the human world. Since it came to limelight and became popularised, biomimicry thinking has been integrated into virtually all sectors with incredible and amazing results. As an important 
and potent sustainability concept, biomimicry aims at achieving the social, environmental and economic dimensions holistically. Despite been a new field and concept, biomimicry has propelled the development of sustainable technologies and materials that are characterised and known to be efficient and effective. Biomimicry solutions for water-related challenges offer the opportunity for increased and efficient water re-use and recycling, wastewater treatment and handling, reclamation of land used for settling ponds, clean-up systems and emergency pollution response for oil spills and land remediation among others. A major advantage is the innovative and enhanced separation capability characteristics of biomimicry technologies aimed at tackling water-related issues. Biomimicry has seen the innovation of renewable sources of energy which is renowned for being the best alternative to the present and unsustainable way of power generation and distribution. Biomimicry smart windows possess variable tinting based on temperature. They can provide significant energy savings by reducing heating and cooling costs in differing weather conditions. Smart walls store thermal energy through phase-change materials which are to be released during periods of lower temperature. With the duo of smart walls and windows, building energy consumption will be drastically reduced. By embracing and adopting biomimicry in its entirety, several innovative and sustainable solutions are bound to be birthed in response to the numerous environmental challenges facing the world. It is, therefore, recommended that governments and international agencies richly fund research and development (R\&D) in the field of biomimicry. By so doing, the discovery and successful development of more efficient and effective solutions and technologies that address each of the global environmental challenges.

\section{Acknowledgements}

The author acknowledges the Postgraduate Funding Support, Postgraduate School, University of Johannesburg, South Africa for awarding the Global Excellence Stature (GES) scholarship in support of the author's doctoral studies.

\section{References}

[1] B. Virakul, Global challenges, sustainable development, and their implications for organizational performance. European Business Review, 27(4), 2015, 430-446. https://doi.org/10.1108/EBR-02-2014-0018

[2] T. Sandler, Global challenges: an approach to environmental, political, and economic problems, Cambridge University Press, 1997.

[3] B. Virakul, DF. Russ-Eft, A model for business responses to global challenges and sustainable development, Social Responsibility Journal. 2019. https://doi.org/10.1108/SRJ-09-2018-0223

[4] WV. Reid, D. Chen, L. Goldfarb, H. Hackman, YT. Lee, K. Mokhele, E. Ostrom, K. Raivio, J. Rockström, HJ. Schellnhuber, A. Whyte, Earth system science for global sustainability: grand challenges, Science. 330(6006), 2010, 916-917. https://doi.org/ 10.1126/science.1196263

[5] World Health Organization, World health statistics 2016: monitoring health for the SDGs sustainable development goals. World Health Organization, 2016.

[6] C. Byrch, K. Kearins, M. Milne, R, Morgan, Sustainable "what"? A cognitive approach to understanding sustainable development, Qualitative Research in Accounting \& Management., 4(1), 2007, 26-52 https://doi.org/10.1108/11766090710732497.

[7] R. Singh, R. Mitra Debnath, Modeling sustainable development: India's strategy for the future, World Journal of Science, Technology and Sustainable Development, 9(2), 2012, 120-135. https://doi.org/10.1108/20425941211244270

[8] M. Yılmaz, A. Bakış, Sustainability in construction sector, Procedia-Social and Behavioral Sciences. 195 (2015) $2253-2262$. https://doi.org/10.1016/j.sbspro.2015.06.312

[9] C.J. Kibert, Sustainable Construction : Green Building Design and Delivery, fourth ed., John Wiley and Sons Inc, Hoboken, New Jersey, 2016.

[10] J. Goss, Biomimicry: Looking to nature for design solutions, Corcoran College of Art and Design, ProQuest Dissertations Publishing, 2009.

[11] J.M. Benyus, Biomimicry: Innovation inspired by nature. William Morrow \& Company, New York, USA, 1997.

[12] GAN. Radwan, N. Osama, Biomimicry, an Approach for Energy Efficient Building Skin Design. Procedia Environmental Sciences. 34 (2016) 178-189. https://doi.org/10.1016/j.proenv.2016.04.017

[13] S. Yurtkuran, G. Kırl, Y. Taneli, Learning from nature: Biomimetic design in architectural education, Procedia-Social and Behavioral Sciences. 89 (2013) 633-639. https://doi.org/10.1016/j.sbspro.2013.08.907

[14] L. Badarnah, Environmental adaptation of buildings through morphological differentiation: a biomimetic approach., Advanced Building Skins Conference, 2018, Bern, Switzerland.

[15] R. Vanaga, A. Blumberga, J. Gusca, D. Blumberga, Choosing the best nature's strategy with the highest thermodynamic potential for application in building thermal envelope using MCA analysis, Energy Procedia, 152 (2018) 450-455. https://doi.org/10.1016/j.egypro.2018.09.252

[16] T.A. Lenau, A.M. Orrù, L. Linkola, Biomimicry in the Nordic Countries. Nordic Working Papers, 2018.

[17] CL. Merrill, Biomimicry of the Dioxygen Active Site in the Copper Proteins Hemocyanin and Cytochrome Oxidase: Part I: Copper (I) Complexes Which React Reversibly with Dioxygen and Serve to Mimic the Active Site Function of Hemocyanin. Part II: Mu-Imidazolato Binuclear Metalloporphyrin Complexes of Iron and Copper as Models for the Active Site Structure in Cytochrome Oxidase (Doctoral dissertation, Rice University) 1982. 
Oguntona and Aigbavboa/ Proceedings of the Creative Construction Conference (2019) 015

https://doi.org/10.3311/CCC2019-015

[18] L. Shu, K. Ueda, I. Chiu, H. Cheong, Biologically inspired design, CIRP Annals - Manufacturing Technology, 60(2), 2011, 673-693. https://doi.org/10.1016/j.cirp.2011.06.001

[19] A. Gamage, R. Hyde, A model based on biomimicry to enhance ecologically sustainable design, Architectural Science Review, 55(3), 2012, 224-235. https://doi.org/10.1080/00038628.2012.709406

[20] M.S. Aziz, A.Y. El Sherif, Biomimicry as an approach for bio-inspired structure with the aid of computation., Alexandria Engineering Journal, 55 (2015) 707-714. https://doi.org/10.1016/j.aej.2015.10.015

[21] A. Marshall, Biomimicry, In Encyclopedia of Corporate Social Responsibility. Springer Berlin Heidelberg, (2015) 174-178.

[22] J.M. Benyus, A biomimicry primer. The Biomimicry Institute and the Biomimicry Guild, 2011.

[23] L. Badarnah, U. Kadri, A methodology for the generation of biomimetic design concepts. Architectural Science Review, 58(2), 2015, $120-133$. https://doi.org/10.1080/00038628.2014.922458

[24] E.B. Kennedy, Biomimetic Buildings: The Emerging Future of Architecture. Global Built Environment Review, 10(1), $2016,1-12$.

[25] M.F.A. Yazdi, R. Zakaria, M. Mustaffar, M.Z. Abd. Majid, R.M. Zin, M. Ismail, K. Yahya, Bio-composite materials potential in enhancing sustainable construction. Desalination and Water Treatment, 52(19-21), 2014, 3631-3636. https://doi.org/10.1080/19443994.2013.854105

[26] The Biomimicry Institute, AskNature, https://asknature.org/?s=\&p=0\&hFR\%5Bpost_type_label\%5D\%5B0\%5D=Inspired\%20Ideas accessed 29 March 2019. 